\title{
Marine diatom growth on different forms of particulate silica: evidence of cell/particle interaction
}

\author{
Antonella Penna ${ }^{1, *}$, Mauro Magnani ${ }^{1}$, Ivana Fenoglio ${ }^{2}$, Bice Fubini ${ }^{2}$, \\ Carlo Cerrano ${ }^{3}$, Marco Giovine ${ }^{4}$, Giorgio Bavestrello ${ }^{5}$ \\ ${ }^{1}$ Centro Biologia Ambientale, Università di Urbino, Viale Trieste 296, 61100 Pesaro, Italy \\ ${ }^{2}$ Dipartimento di Chimica Inorganica, Chimica Fisica e Chimica dei Materiali, Università di Torino, Via P. Giuria 9, \\ 10125 Torino, Italy \\ ${ }^{3}$ Dipartimento per lo Studio del Territorio e delle sue Risorse, Università di Genova, Corso Europa 26, 16132 Genova, Italy \\ ${ }^{4}$ Istituto Policattedra Chimica Biologica,Università di Genova, Viale Benedetto XV, 16132 Genova, Italy \\ ${ }^{5}$ Istituto di Scienze del Mare, Università di Ancona, Via Brecce Bianche, 60131 Ancona, Italy
}

\begin{abstract}
The influence of particulate silica sources on growth and silicon uptake of 3 diatom species: Cylindrotheca fusiformis, Navicula sp., and Skeletonema costatum, was investigated. Each diatom strain was incubated in controlled conditions, with mineral (quartz sand and 2 pure quartz dusts with variable degree of hydrophilicity/hydrophobicity) and biogenic (diatomaceous earth and sponge spicules) silica substrates. Mineral sources were all crystalline, while the biogenic substrates were mostly amorphous. Each diatom species showed a different growth pattern with the various particulate silica substrates, none of which related to the rate of silicon dissolution in the growth medium: S. costatum grew better in presence of the quartz sand; while Navicula sp. and C. fusiformis showed higher growth values with the hydrophobic quartz particles. In contrast, low levels of growth of the 3 diatoms were found in the presence of the biogenic amorphous silica substrates. The high values of the silicon uptake of all diatom species in the presence of the crystalline substrates in culture conditions seemed to confirm the preferred exploitation of the dissolved silicon from crystalline sources with respect to the amorphous mineral substrates. Thus, it could be hypothesized that the dissolved silicon uptake by marine diatoms was not only mediated by solubilized oligomeric silica, but a direct interaction between diatom cell and particulate mineral substrates. Such chemical/physiological interaction can be highly specific either for the different diatom species or silica particles. A chemical model of a possible role of some organic compounds involved in the uptake of dissolved silicon from particulate silica sources by marine diatoms was suggested, and the potential ecological significance of these findings is discussed.
\end{abstract}

KEY WORDS: Biomineralization - Diatoms - Mineral substrates · Silicon uptake - Crystalline amorphous silica $\cdot$ Biogenic amorphous silica $\cdot$ Hydrophilicity/Hydrophobicity

\section{INTRODUCTION}

Diatoms are the predominant siliceous organisms in the marine environment and the major component of phytoplankton. They account for $40 \%$ of total primary production in the sea, and tend to deplete the limiting inorganic nutrient supply in the photic zone (Barnes \& Mann 1991). Silicon availability is a key factor in the regulation of diatom growth, as it constitutes the diatom cell wall in its polymerized form, opaline silica (Shipe \& Brzezinski 1999). Silicon is supplied to the ocean both dissolved as monomeric or oligomeric form or as solid particulates in variable size and crystallinity. Dissolved silicon can be loaded by river runoff (Millero \& Sohn 1997) as well as by the dissolution of particulate silicon present in the lithogenic and biogenic systems. In the 
sea the biogeochemical dissolution of this mineral is controlled by temperature, zooplankton grazing, diatom sinking (Nelson et al. 1996) and bacterial activity (Bidle \& Azam 1999). In turn, the requirement of silicon by diatom growth negatively affects the silicon balance in the marine ecosystem (Jézéquel et al. 2000).

Studies on the uptake of dissolved silicon by diatom cells (Paasche 1973) have demonstrated that active silicon transport and the specific Si-dependent celldivision rate follow Michaelis-Menten kinetics (Taguchi et al. 1987, Gensemer et al. 1993). Silicon transport inside the cell seems to be carrier-mediated, and in marine diatoms the ion-carrier can be $\mathrm{Na}^{+}$dependent (Bhattacharya \& Volcani 1980) with metabolic energy supply (Lewin 1955, Azam et al. 1974). The carrier function of silicon transport inside the cell can be mediated by the action of a protein: the silicon transporter (SIT), present in marine and freshwater diatoms (Hildebrand et al. 1998). Silica deposition and morphogenesis of the cell wall seems to occur in a specialized compartment: the Silica Deposition Vesicle, known as SDV (Vrieling et al. 1999). In the SDV, the acidic environment contributes to the silicic acid polymerization into amorphous hydrated silica onto an organic template (proteins, polysaccharides, lipids), that drives the frustule silicification and morphogenesis (Kröger et al. 2000).

Generally it is assumed that diatoms take up silicon as undissociated silicic acid, $\mathrm{Si}(\mathrm{OH})_{4}$, at $\mathrm{pH} 8.0$ from the marine environment (Lewin 1962, Del Amo \& Brzezinski 1999). This is the dominant form, constituting $97 \%$ of total dissolved $\mathrm{Si}(\mathrm{dSi})$; the remainder is essentially $\mathrm{SiO}(\mathrm{OH})_{3}{ }^{-}$. Despite numerous studies focused on characterizing the chemistry of silicon uptake and deposition (Volcani 1981, Riedel \& Nelson 1985, Brzezinski et al. 1990), the influence on diatom growth of different particulate silica forms as a silicon source has not been studied so far. This issue is of high interest in marine coastal water systems, where dissolved silicon can be depleted during diatom blooms, although both siliceous lithogenic material and biogenic silica from settled diatoms are abundant.

The aim of this work is to test the ability of 3 common benthic and planktonic diatom species, Navicula sp. and Cylindrotheca fusiformis and Skeletonema costatum, respectively, to take up silicon from various lithogenic and biogenic amorphous sources, such as crystalline quartz (natural quartz sand, hydrophilic and hydrophobic quartz dusts), diatomaceous earth and sponge spicules by measuring the diatom biomass increase and silicon uptake in culture conditions. Furthermore, a hypothetical chemical model was investigated to explain whether the response of marinediatom biomass-increases toward the different particulate silica substrates can be mediated by a sur- face interaction, or whether the response is due to the variations in solubility of the different silica forms. It can be suggested that organic compounds, such as ascorbate and/or catechol, are excreted by the cell and partially mediate the solubility of the silica mineral substrates in the medium.

\section{MATERIALS AND METHODS}

Diatom cultures. The diatom species Skeletonema costatum, Strain CBA1 (Centro Biologia Ambientale), Cylindrotheca fusiformis, Strain CBA2 and Navicula sp., Strain CBA4, were maintained in $\mathrm{f} / 2$ enriched seawater medium with added solution of sodium silicate (Guillard 1975) at $17 \pm 1^{\circ} \mathrm{C}$ under a photon flux of $100 \mu \mathrm{E} \mathrm{m}^{-2} \mathrm{~s}^{-1}$ in a 14:10 h light:dark cycle.

Si-free media. Artificial seawater, as ASPM (Artificial Seawater Provasoli-McLachlan) base (Guillard 1975), was prepared to produce Si-free seawater. The above seawater was enriched as $\mathrm{f} / 2$, without added dissolved silicon $(\mathrm{dSi})$. The $\mathrm{pH}$ of the final medium was 8.0. Bacteria-free medium was obtained by filtering $100 \mathrm{ml}$ aliquots of the medium through $0.2 \mu \mathrm{m}$ cellulose acetate filters (Nalgene) into $550 \mathrm{ml}$ sterile polystyrene flasks.

Silica mineral substrates. Diatoms were grown in the presence of silicon supply from different silica mineral substrates. The silica minerals used have either a mineral crystalline (natural quartz sand or hydrophilic and hydrophobic quartz dusts) or biogenic amorphous origin (diatomaceous earth and sponge spicules). Natural quartz sand (BDH) is comprised of spherical grains, 125 to $250 \mu \mathrm{m}$ in diameter, with an internal texture comprised of aggregates of polygonal granuloblastic quartz. Hydrophilic quartz (Min-U-Sil 5, Berkeley Springs Plant, ITC) is a highly pure commercial dust $\left(\mathrm{SiO}_{2}, 98.7 \%\right)$ obtained by crushing quartz crystals: the grinding process causes the exposure of fresh surfaces with a high reactivity due to the presence of surface radicals and trace metal impurities. Such quartz particles (mean diameter $1.7 \mu \mathrm{m}$ ) are characterized by a high hydrophilicity due to the abundance of silanols at the surface, generated by the contact of water vapour with the newly formed surfaces (Fubini et al. 1999). Hydrophobic quartz dust is obtained from the above hydrophilic quartz by heating it to $800 \pm 1{ }^{\circ} \mathrm{C}$ in a quartz container connected to a vacuum line. This treatment causes the partial condensation at the surface of the hydrophilic silanols ( $\mathrm{Si}-\mathrm{OH})$ into hydrophobic siloxanes (Si-O-Si). The degree of hydrophilicity of the 2 dusts have been evaluated by measuring the heat of water vapour adsorption using the microcalorimetric technique (Bolis et al. 1992). Diatomaceous earth (SigmaAldrich, D-5384) was purified by acid washing and then 
calcined $\left(\mathrm{SiO}_{2}, 97.5 \%\right)$, according to the manufacturer's instructions. This powder, although mostly amorphous, is partially crystallized into cristobalite. Siliceous spicules were obtained from the common Mediterranean demosponge Petrosia ficiformis; these were comprised of needle-like monaxonic elements (oxeas, styles and strongyles) 110 to $240 \mu \mathrm{m}$ in length and 18 to $25 \mu \mathrm{m}$ in width. The spicules were obtained from a large specimen dissolved in daily changes of $\mathrm{H}_{2} \mathrm{O}_{2}$ for $2 \mathrm{wk}$, and after, rinsed twice a day for $5 \mathrm{~d}$ in distilled $\mathrm{H}_{2} \mathrm{O}$ and dried at $100 \pm 1^{\circ} \mathrm{C}$ for $2 \mathrm{~h}$. Diatom cultures were also grown in the presence of silicon as orthosilicate $\left[\mathrm{Si}(\mathrm{OH})_{4}\right]$, derived from a $\mathrm{Na}_{2} \mathrm{SiO}_{3}$ stock solution. This was considered the control for soluble silicon supply condition.

Silicon-supply concentration and biomass increase. To enable the growth of the 3 diatom species in $\mathrm{dSi}$ non-limiting conditions, we assessed the dSi concentration by measuring the dSi uptake by the diatom species in the presence of each particulate silica substrate. The dSi concentration of $360 \mu \mathrm{M}$ was required to exceed the silicon requirement for each diatom species during all phases of $14 \mathrm{~d}$ growth (data not shown and experiments not described).

In this study, before the growth experiments each silica crystalline and amorphous mineral was weighted to obtain a final concentration of chemically dSi, after $14 \mathrm{~d}$ incubation, of $360 \mu \mathrm{M}$ to be inoculated in each culture medium. The chemical solubility of the various silica mineral substrates was assessed by measuring the total amount of dSi after a $14 \mathrm{~d}$ period of incubation in cellfree cultures (Table 1). The silica mineral substrates were separately weighted and incubated in $100 \mathrm{ml}$ of $\mathrm{f} / 2$ artificial seawater, $\mathrm{pH} 8.0$, at $17 \pm 1^{\circ} \mathrm{C}$ for $14 \mathrm{~d}$. The $\mathrm{dSi}$ content of each flask was estimated at $2 \mathrm{~d}$ intervals. The supernatant was separated by centrifugation (5000 $\times g, 30 \mathrm{~min}$ ) and the dSi concentration was measured spectrophotometrically using the Strickland \& Parsons (1972) molybdate method. To perform the biomass increase experiments, each culture flask, containing the different silica mineral substrates, was inoculated with the late-exponential phase of cells $\left(1.0 \times 10^{6} \mathrm{cells} \mathrm{m}^{-1}\right)$. Axenic cultures $(100 \mathrm{ml})$ of Cylindrotheca fusiformis,

Table 1. Silica mineral substrate amounts used in each culture medium for the marine diatom growth experiments and relative solubility during the $14 \mathrm{~d}$ incubation period

\begin{tabular}{|lcrrr|}
\hline Silica minerals & Weight & \multicolumn{3}{c|}{ Solubility $(\mu \mathrm{M})$} \\
& $(\mathrm{g})$ & Day 4 & Day 8 & Day 14 \\
\hline Quartz sand & 11 & 180 & 190 & 360 \\
Hydrophilic quartz & 0.5 & 300 & 335 & 360 \\
Hydrophobic quartz & 1.0 & 220 & 300 & 360 \\
Spicule sponge & 1.1 & 53 & 80 & 360 \\
Diatomaceous earth & 0.6 & 240 & 264 & 360 \\
\hline
\end{tabular}

Navicula sp. and Skeletonema costatum were grown in nutrient-enriched f/2 artificial seawater media with $\mathrm{dSi}$ non limiting supply concentration furnished by the crystalline and/or amorphous silica mineral substrates, as previously described, at $17 \pm 1^{\circ} \mathrm{C}$ under a $14: 10 \mathrm{~h}$ light:dark cycle and continuous photon flux rate of $100 \mu \mathrm{E} \mathrm{m}^{-2} \mathrm{~s}^{-1}$. Samples $(100 \mathrm{ml})$ were harvested sequentially at $2 \mathrm{~d}$ intervals during the incubation period and cell biomass was estimated by analyzing the chl a content (APHA 1995). Cell density determination by microscopy was made difficult due to the silica mineral sands covering the diatom cells.

Uptake of dissolved silicon. Total dSi in the medium was estimated at $2 \mathrm{~d}$ intervals during the $14 \mathrm{~d}$ incubation period; cell-free samples (100 ml of medium) were collected during the harvesting of cells onto a $0.45 \mu \mathrm{m}$ nitrocellulose filter. The uptake of dSi by diatom cells was calculated by subtracting the value of the dSi content at each $2 \mathrm{~d}$ interval from the value of the $\mathrm{dSi}$ content estimated in the cell-free incubation on the same interval day (see the section 'Silicon-supply concentration and biomass increase'). The concentration of $\mathrm{dSi}$ was determined according to the molybdate method described by Strickland \& Parsons (1972).

Particulate silica solubility in the $\mathrm{f} / \mathbf{2}$ medium and ascorbate and catechol solution. The solubility of the different particulate silica substrates in the $\mathrm{f} / 2$ artificial seawater was performed by incubating each silica mineral $(0.5 \mathrm{~g})$ in the medium, $\mathrm{pH} 8.0,4 \pm 1^{\circ} \mathrm{C}$, in the dark. The concentration of dSi was determined according to the molybdate method described by Strickland \& Parsons (1972).

The effect of the ascorbate and catechol on silica solubility of the 5 different silica substrates was determined by incubating each mineral in a $40 \mathrm{mM}$ solution of sodium ascorbate or catechol (Sigma-Aldrich) in $\mathrm{f} / 2$ artificial seawater, $\mathrm{pH} 8.0,4 \pm 1^{\circ} \mathrm{C}$, in the dark. The $\mathrm{dSi}$ was then measured as described previously. The concentration of ascorbic acid and catechol was monitored spectrophotometrically during the $14 \mathrm{~d}$ incubation by measuring the UV absorption at 265 and $230 \mathrm{~nm}$ respectively (Fenoglio et al. 2000); to ensure that molecules are present, as catechol and ascorbic acid, in the solution during the $14 \mathrm{~d}$ treatment, they may be oxidized by reacting with transition metals in solution and dissolved oxygen.

\section{RESULTS}

\section{Biomass increase and silicon uptake}

Biomass increase and silica uptake of the 3 diatom species are shown in Figs. 1, 2 \& 3. The diatombiomass increases were estimated under 5 different 

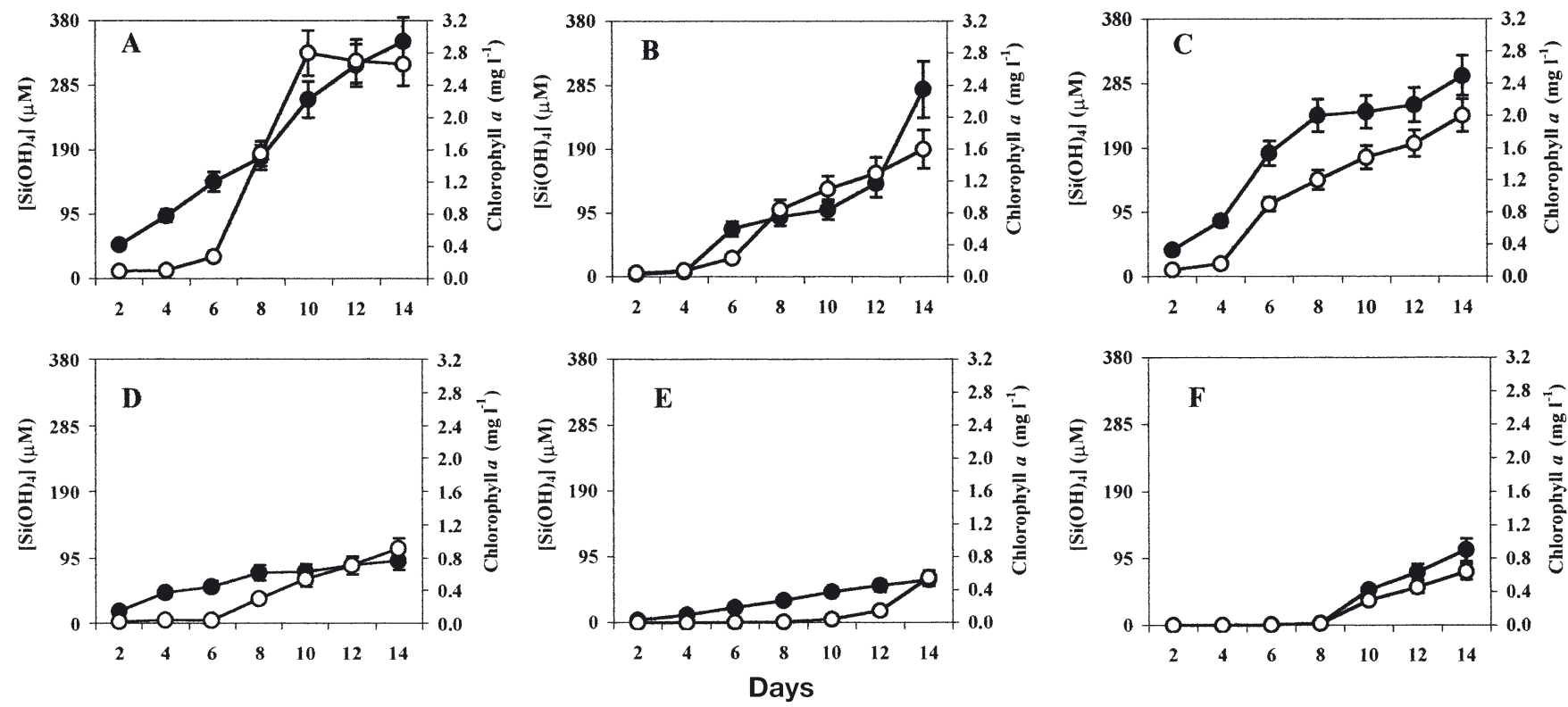

Fig. 1. Skeletonema costatum. Biomass increase (o) and dissolved silicon uptake (•) of Strain CBA1 under different silica supply conditions: (A) quartz sand, (B) hydrophilic quartz dust, (C) hydrophobic quartz dust, (D) diatomaceous earth, (E) sponge spicules, (F) ortho-silicate. Biomass increases were measured as chl a content of $S$. costatum in batch cultures. Values represent means of 3 replicate cultures $\pm 1 \mathrm{SD}$
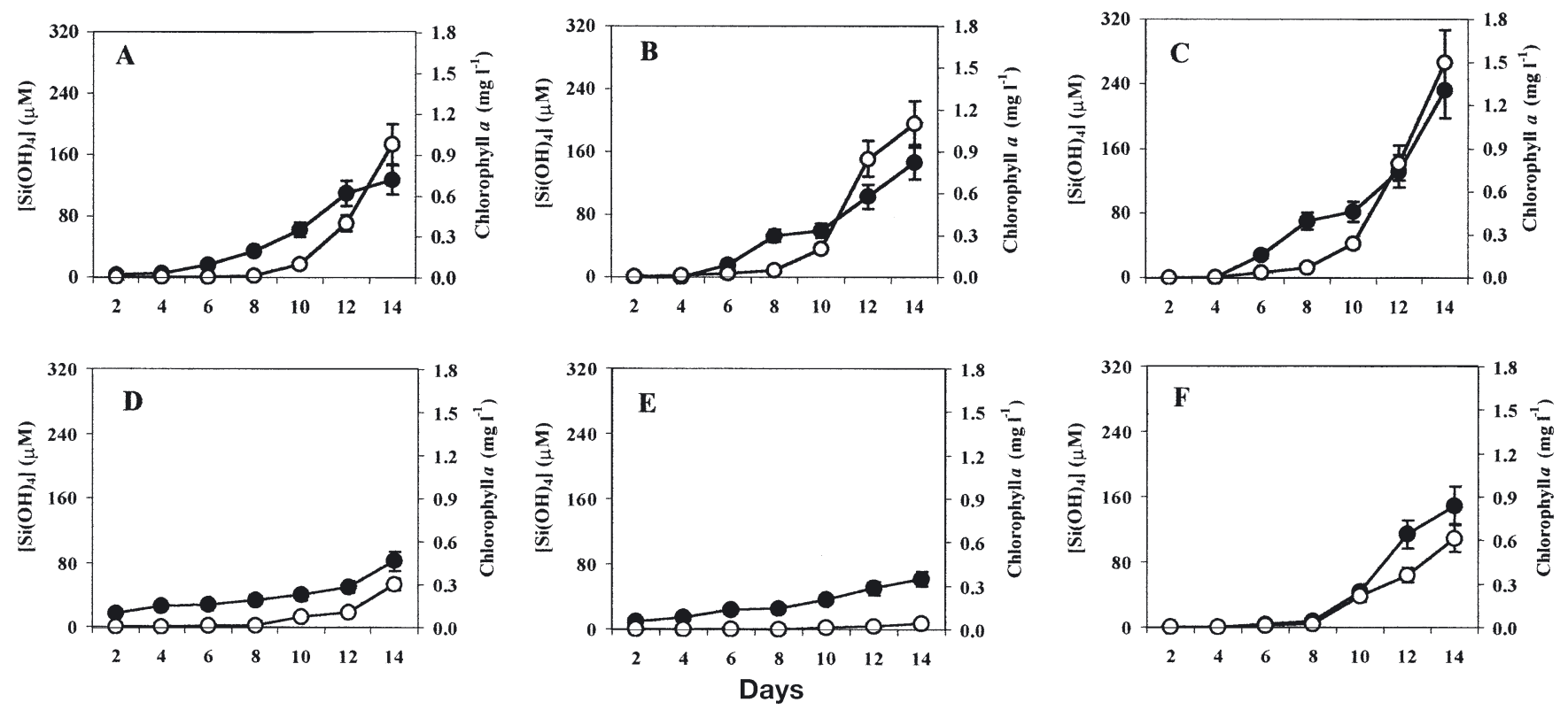

Fig. 2. Cylindrotheca fusiformis. Biomass increase (o) and dissolved silicon uptake (•) of Strain CBA2 under different silica supply conditions: (A) quartz sand, (B) hydrophilic quartz dust, (C) hydrophobic quartz dust, (D) diatomaceous earth, (E) sponge spicules, (F) ortho-silicate. Biomass increases were measured as chl a content of $C$. fusiformis in batch cultures. Values represent means of 3 replicate cultures $\pm 1 \mathrm{SD}$

silicon supply conditions, i.e. with either various crystalline or amorphous silica substrates. The biomass increase curves of the 3 species were characterized by exponential and early stationary phases; however, the biomass-increase pattern depended either on the diatom species or silica source. All diatom species grew faster under silica crystalline substrates, such as quartz sand (A in Figs. 1-3), hydrophilic (B) and hydrophobic pure quartz (C); Skeletonema costatum

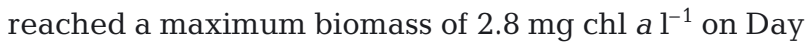



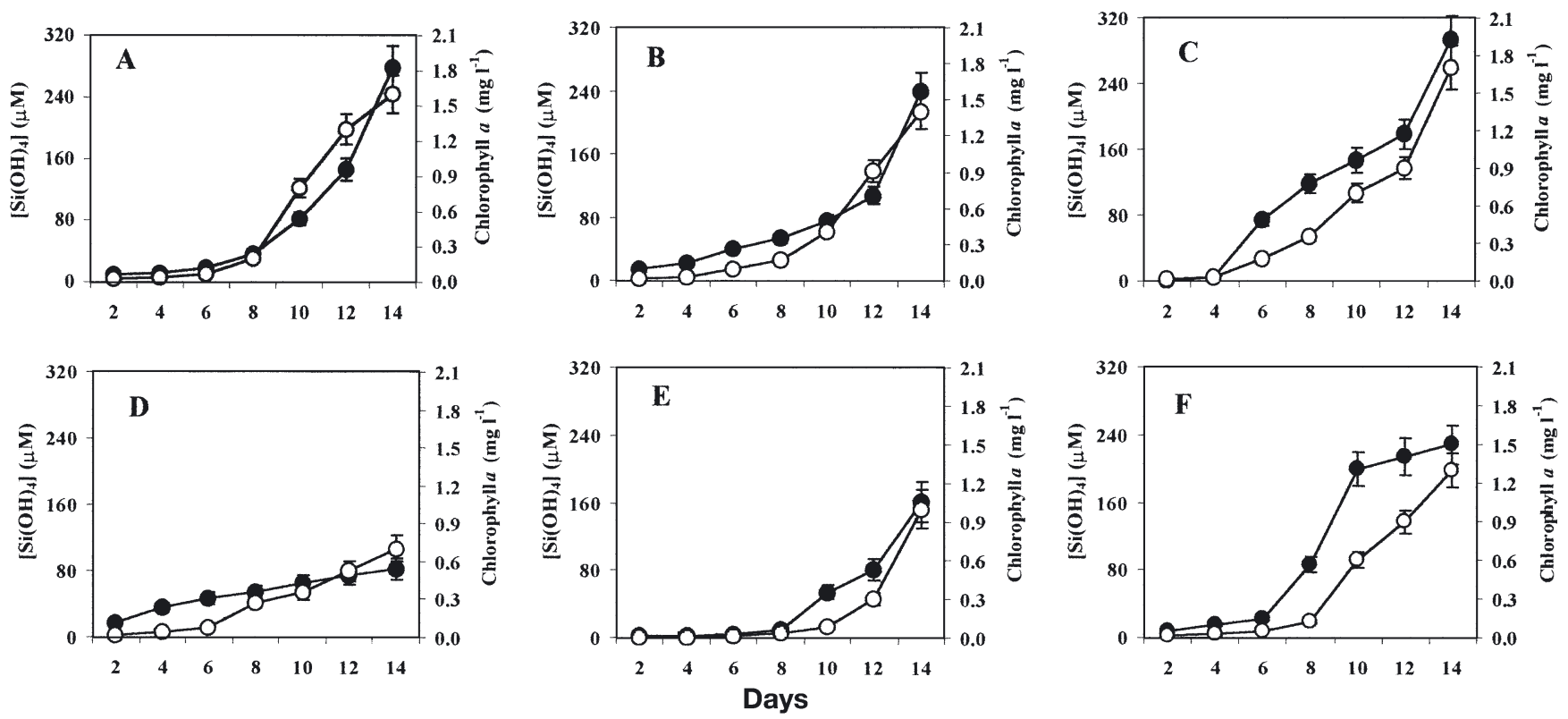

Fig. 3. Navicula sp. Biomass increase (o) and dissolved silica uptake (•) of Strain CBA4 under different silicon supply conditions: (A) quartz sand, (B) hydrophilic quartz dust, (C) hydrophobic quartz dust, (D) diatomaceous earth, (E) sponge spicules, (F) ortho-silicate. Biomass increases were measured as chl a content of Navicula sp. in batch cultures. Values represent means of 3 replicate cultures $\pm 1 \mathrm{SD}$

10 of the exponential growth phase under natural quartz sand supply conditions. Cylindrotheca fusiformis and Navicula sp. biomass reached their highest values of 1.5 and $1.7 \mathrm{mg} \mathrm{chl} \mathrm{a} \mathrm{l}^{-1}$, respectively, on Day 14 of the exponential growth phase under hydrophobic quartz-supply conditions. S. costatum reached the stationary phase faster (on Day 10) than the other species under quartz sand supply conditions; indeed, except for $S$. costatum under quartz sand, the other species did not reach the stationary phase during the experiment (14 d) in any of the supply conditions. All species displayed lower growth under amorphous silica mineral substrates, such as diatomaceous earth (D in Figs. 1-3) and sponge spicules (E), without reaching the stationary phase. Under dissolved ortho-silicate supply conditions, all species grew less compared to the diatoms with the crystalline silica substrates, but in general they grew better than in amorphous silica supply conditions. The silicon uptake by C. fusiformis, Navicula sp. and $S$. costatum increased during the growth phase, following the corresponding trend of the diatom biomass increases.

The ortho-silicate supply condition was the common silicate source used for culture maintenance and was used as a control here. The results of diatom biomass increases with different silica mineral sources compared to the ortho-silicate are reported in Fig. 4. During the exponential phase (on Day 8), all diatom species exhibited higher values of biomass in the presence of the various crystalline silica supply conditions compared to the ortho-silicate supply ( $\mathrm{p}<0.005)$, except for Cylindrotheca fusiformis, which exhibited a lower biomass increase under the quartz sand supply condition. Under the sponge-spicule substrate the algal biomass did not show a detectable increase, as the chl a values were lowest compared to the other silicon-supply conditions ( $p<0.001)$. Diatomaceous earth supply seemed to favour algal growth when compared to the control ( $p<0.001)$ in Navicula sp. and Skeletonema costatum.

\section{Effect of ascorbate and catechol on the solubility of mineral silica substrates}

The biomass increase of different diatom species in the presence of various particulate silica forms may be explained by an improved solubility of the crystalline silica substrates caused by a molecule secreted by diatoms in response to the presence of the different substrates. The order of diatom growth, in fact, recalls the effect caused by molecules containing a planar diol moiety such as ascorbic acid and catechol, which increase the solubility of crystalline silica more than the amorphous silica substrates (Bennet 1991, Fubini et al. 1999). To demonstrate the possible involvement of a similar mechanism, the solubility of the various particulate silica substrates was measured in the presence of ascorbic acid and catechol in a cell-free system in the same culture medium condi- 
tions used for diatoms. The amount of monomeric silicon dissolved from each of the 5 silica substrates was measured after $14 \mathrm{~d}$ of dark incubation in the following conditions: (1) artificial seawater medium (f/2) at $\mathrm{pH} 8.0$; (2) $50 \mathrm{mM}$ ascorbic acid solution in artificial seawater medium (f/2) at pH 8.0; (3) $50 \mathrm{mM}$ catechol solution with artificial seawater medium (f/2) at $\mathrm{pH} 8.0$ (Fig. 5). In artificial seawater medium f/2 (Fig. 5A), the 2 pure quartz dusts and diatomaceous earth appeared to be more soluble (442 to $595 \mu \mathrm{M}$ of $\left.\mathrm{Si}[\mathrm{OH}]_{4 i} \mathrm{p}<0.001\right)$ than quartz sand and sponge spicules. The effect of ascorbic acid and catechol are reported in Fig. 5B as percentage increase of dSi compared to the solubility in artificial seawater. Both ascorbic acid or catechol increased the amount of dSi from all the silica substrates tested. The highest effect due to ascorbic acid was detected with the 2 pure quartz dusts (hydrophilic and hydrophobic); the catechol increased the solubility of all quartz substrates much more than that of the amorphous silica substrates.
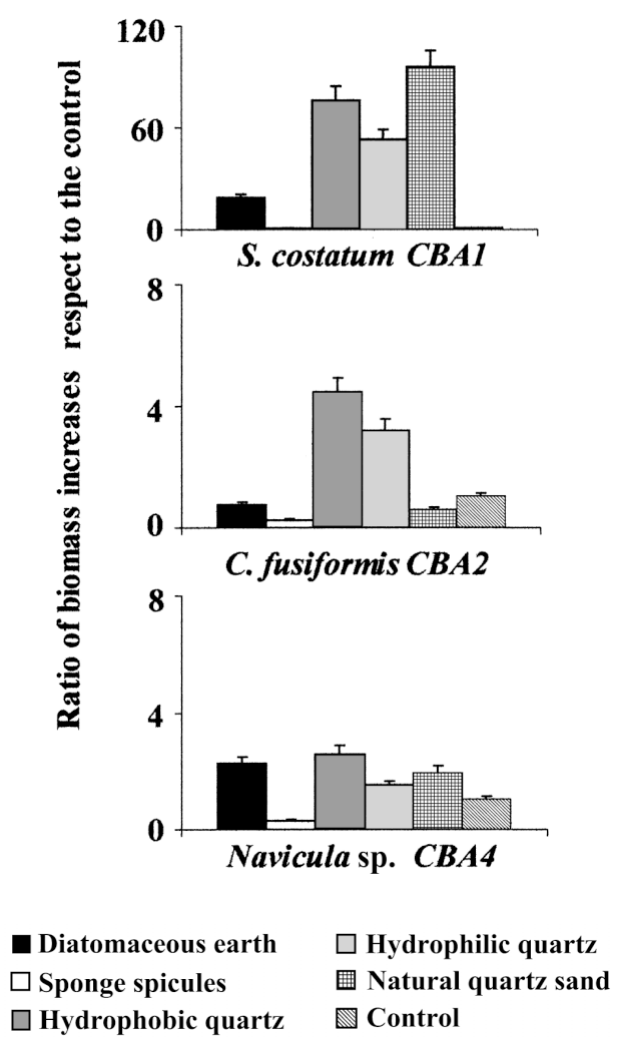

Fig. 4. Skeletonema costatum, Cylindrotheca fusiformis and Navicula sp. Biomass increase of the 3 marine diatoms under different silicon supply conditions compared to the orthosilicate supply condition (control). Data were expressed as the ratio of biomass increase values obtained with the various silica minerals with respect to biomass increase values obtained with ortho-silicate, for which a unit value was assumed. Biomass values ( $\mathrm{chl}$ a) were measured on Day 8 of the exponential phase. Values represent means of 3 replicate cultures $\pm 1 \mathrm{SD}$

\section{DISCUSSION}

\section{Growth and ecology of diatoms}

The first goal of this work was to show that the nature of the various particulate silica substrates affected marine diatom growth. The 3 species grew much better with crystalline than amorphous (diatomaceous earth) substrates, free from their solubility in artificial seawater. Accordingly, quartz dusts were more readily consumed, while diatom cells presented low uptake of amorphous biogenic silica, considering the low biomass values found in culture flasks. This could suggest a hypothetical surface driven uptake mechanism: i.e. marine diatoms might be able to make bio-available dissolved silicon from particulate silica by excretion of some compounds, which facilitate silicon dissolution in silicic acid, either by cell-particle contact for benthic diatoms or by diffusion into the medium for pelagic species. In fact, it was observed (data not shown) that in the same growth media used in these experiments, the benthic diatoms Cylindrotheca fusiformis and Navicula sp. tended to settle only on the quartz sand and not on the amorphous silica substrates, implying a direct interaction between cells and substrate particle surfaces. A similar phenomenon has been found in the marine sponge Chondrosia reniformis, where the interactions of the sponge cell pinacocytes with natural quartz sand produced a rapid dissolution of the quartz grains, while no dissolution was observed upon interaction with opaline biogenic silica (Bavestrello et al. 1995).

In the ocean, the major sources of silicon are both terrestrial, in the form of continental and glacial drainages, and marine, in the form of submarine volcanisms and hydrothermal events (DeMaster 1981); further, a large amount of silicon results from internal regeneration or nutrient input by river discharge. $\mathrm{Si}(\mathrm{OH})_{4}$ is biologically available for all marine organisms constituted of silica skeletal structures (diatoms, silicoflagellates, radiolarians, heliozoans and sponges); diatoms, representing $80 \%$ of these organisms, are able to remove nearly all dissolved silicon from the open-ocean water surface. The present data shows that diatoms are able to better obtain a dissolved silicon supply from quartzitic mineral substrates than soluble ortho-silicate, commonly used as a source of silicon in the $\mathrm{f} / 2$ medium.

Although the silicon soluble form, i.e. $\mathrm{Si}(\mathrm{OH})_{4}$, is generally considered the only available source of silicon for aquatic biota, there is some evidence that silica sponges may dissolve and use quartz or insoluble silicates as a dSi source. Gemmules of Spongilla lacustris reared in silicon-free freshwater may produce a complete spicular complement, using different kinds of silicates, such as quartz sand on the aquarium bottom (Jørgensen 1944). 
In this work, the selectivity of the diatom biomass increase and dSi uptakes in the presence of different particulate silica was unrelated to the amount of silicon dissolved from various silica substrates used in the experiments. In fact, diatomaceous earth and hydrophilic quartz exhibited higher solubilities, but none of the diatom species studied grew better with the 2 substrates, especially the diatomaceous earth. The present findings suggest that silicon uptake by diatoms may also be mediated by an extracellular compound, which influences the silica dissolution rate and/or facilitates the direct uptake of $\mathrm{dSi}$ as $\mathrm{Si}(\mathrm{OH})_{4}$ at the solid/liquid interface.

\section{Effect of diols on the solubility of the silica substrates}

It is well known that the rate of silica dissolution is greatly affected by crystallinity, particle size and impurity presence, such as aluminium or iron. The solubility of different particulate silica forms in equilibrium conditions is not easy to determine, due to amorphous layer formation at the surface of crystalline forms during the dissolutionredeposition process. A true equilibrium of solubility is not reached; thus most authors report the rate of dissolution rather than the solubility itself (Iler 1979). The different solubility of the silica forms tested is shown in Fig. 5A. The high solubility of hydrophilic and hydrophobic quartzes compared to quartz sand was due to the origin of these samples: the grinding processes produced a disturbed layer at the surface, which dissolved rapidly. Spicules, as expected, exhibited a low solubility, while the relatively high solubility of diatomaceous earth is difficult to compare with the data reported in the literature (Lewin 1961, Kamatani 1971) as it depends on several factors, such as age, impurity presence and origin. The solubility of the silica substrates does not account for the biomass increase and silicon uptake results of the 3 diatoms, and the excretion of a molecule able to modify the silica substrate solubility could be hypothesized.

Similarly to catechol, which exhibits hexacoordinate complexes between silicon and planar diol moiety (Kinrade et al. 2001), ascorbic acid exhibits a planar 1, 2 diol moiety, and the formation of an organosilicon complex between ascorbic acid and silicon has been hypothesized to explain the increased solubility of silica in the presence of ascorbic acid (Fenoglio et al. 2000). The author reported the ability of ascorbic acid to preferentially dissolve quartz rather than amorphous silica. A selective effect is also found in some marine sponges, which are able to dissolve quartz sand but not opaline amorphous spicules (Bavestrello et al. 1995). In this study, a similar chemical model mediated by ascorbic acid and/or cathecol action on the solubility of different silica substrates was examined. The data showed that ascorbic acid and catechol drastically increased the solubility of the silica substrates.

A similar chemical action probably acts in living systems such as diatom cells, which can continuously produce extracellular organic compounds like ascorbic acid at the silica mineral surface. The distinct biomass increases observed with the 3 diatom species in the presence of the 2 pure quartz dusts, differing in surface hydrophobicity, suggests that solid/liquid interface processes are occurring. The thermal treatment, employed to prepare the hydrophobic quartz, deeply decreases the number of silanols able to form hydrogen bonding (Fubini et al. 1993). This may account for the slightly lower seawater solubility of the hydrophobic quartz. However, diatom biomass increased 
when the pure hydrophilic quartz was converted into the hydrophobic one; this may be due to an enhancement of diatom adhesion onto the silica particles, probably mediated by protein-surface adsorption.

The data obtained in this work add new findings to knowledge of diatom silicon-metabolism; diatoms may be partially able to make bio-available silicon from particulate silica by excreting organic compounds, probably containing a diol moiety, facilitating silicon dissolution, either by cell-particle contact for benthic diatoms or molecular diffusion for pelagic species.

Acknowledgements. We thank anonymous reviewers for helpful comments and suggestions. This work was supported by the Italian Ministero Università e Ricerca Scientifica/ Programmi di Ricerca Scientifica Richiesta Cofinanziamento 1999 Grant.

\section{LITERATURE CITED}

APHA (American Public Health Association) (1995) Standard methods for the examination of water and wastewater, 19th edn. APHA, Washington, DC

Azam F, Hemmingsen BB, Volcani BE (1974) Role of silicon in diatom metabolism. V. Silicic acid transport and metabolism in the heterotrophic diatom Nitzschia alba. Arch Microbiol 97:103-114

Barnes RSK, Mann KH (1991) Fundamentals of aquatic ecology. Blackwell Science, London

Bavestrello G, Arillo A, Benatti U, Cerrano C and 6 others (1995) Quartz dissolution by the sponge Chondrosia reniformis (Porifera, Demospongiae). Nature 378:374-376

Bennet PC (1991) Quartz dissolution in organic-rich aqueous systems. Geochim Cosmochim Acta 55:1781-1797

Bhattacharya P, Volcani BE (1980) Sodium-dependent silicate transport in the apochlorotic marine diatom Nitzschia alba. Proc Natl Acad Sci USA 77:6386-6390

Bidle KD, Azam F (1999) Accelerated dissolution of diatom silica by marine bacterial assemblages. Nature 397:508-512

Bolis V, Fubini B, Marchese L, Martra G, Costa D (1992) Hydrophilic and hydrophobic sites on dehydrated crystalline and amorphous. J Chem Soc Lond Faraday Trans 87:497-505

Brzezinski MA, Olsen RJ, Chisholm SW (1990) Silicon availability and cell-cycle progression in marine diatoms. Mar Ecol Prog Ser 67:83-96

Del Amo Y, Brzezinski MA (1999) The chemical form of dissolved Si taken up by marine diatoms. J Phycol 35: $1162-1170$

DeMaster (1981) The supply and accumulation of silica in the marine environment. Geochim Cosmochim Acta 45: 1715-1732

Fenoglio I, Martra G, Coluccia S, Fubini B (2000) Possible role of ascorbic acid in the oxidative damage induced by inhaled crystalline silica particles. Chem Res Toxicol 13: $2-6$

Fubini B, Bolis V, Cavenago A, Garrone E, Ugliengo P (1993) Structural and induced heterogeneity at the surface of some $\mathrm{SiO}_{2}$ polymorphs evidenced by the adsorption of various probe molecules. Langmuir 9:2712-2721

Fubini B, Zanetti G, Altilia S, Tiozzo R, Lison D, Saffiotti U (1999) Relationship between surface properties and cellular responses to crystalline silica: studies on heat-treated cristobalite. Chem Res Toxicol 12:737-745

Gensemer RW, Smith REH, Duthie HC (1993) Comparative effects of $\mathrm{pH}$ and aluminium on silica-limited population of Asterionella-Ralfsii-var-americana (Bacillariophyceae). J Phycol 29:35-44

Guillard RRL (1975) Culture of phytoplankton for feeding marine invertebrate animals. In: Smith WL, Chanley $\mathrm{MH}$ (eds) Culture of marine invertebrate animals. Plenum Press, New York, p 29-60

Hildebrand M, Dahlin K, Volcani BE (1998) Characterization of a silicon transporter gene family in Cylindrotheca fusiformis sequences, expression analysis and identification of homologs in other diatoms. Mol Gen Genetic 260: $480-486$

Iler RK (1979) The chemistry of silica. John Wiley \& Sons, New York

Jézéquel VM, Hildebrand M, Brzezinski MA (2000) Silicon metabolism in diatoms: implications for growth. J Phycol 36:821-840

Jørgensen CB (1944) On the spicule formation of Spongilla lacustris. Det Kgl Danske Videnskabernes Selskab Biologiske Meddelelser Bind IX 7:1-45

Kamatani A (1971) Physical and chemical characteristics of biogenous silica. Mar Biol 68:91-96

Kinrade SF, Schach AS, Hamilton RJ, Knight CTG (2001) NMR evidence of pentaoxo organosilicon complexes in diluted neutral aqueous silicate solution. Chem Comm $1564-1565$

Kröger N, Deutzmann R, Bergsdorf C, Sumper M (2000) Species-specific polyamines from diatom control silica morphology. Proc Natl Acad Sci USA 97:14133-14138

Lewin JC (1955) Silicon metabolism in diatoms. III. Respiration and silicon uptake in Navicula pelliculosa. J Gen Microbiol 3:427-433

Lewin JC (1961) The dissolution of silica from diatom walls. Geochim Cosmochim Acta 21:182-198

Lewin JC (1962) Silicification. In: Lewin RA (ed) Physiology and biochemistry of algae. Academic Press, New York, p 445-455

Millero FJ, Sohn ML (1997) Chemical oceanography. CRC Press, Boca Raton, FL

Nelson DM, DeMaster DJ, Dunbar RB, Smith WO Jr (1996) Cycling of organic carbon and biogenic silica in the Southern Ocean: estimates of water-column and sedimentary fluxes on the Ross Sea continental shelf. J Geophys Res 101:18519-18532

Paasche E (1973) Silicon and ecology of marine planktonic diatoms. II. Silicate-uptake kinetics in five diatom species. Mar Biol 19:262-269

Riedel GF, Nelson DM (1985) Silicon uptake by algae with no known $\mathrm{Si}$ requirement. II. Strong $\mathrm{pH}$ dependence of uptake kinetic parameters in Phaeodactylum tricornutum (Bacillariophyceae). J Phycol 21:168-171

Shipe R, Brzezinski M (1999) A study of Si deposition synchrony in Rhizosolenia (Bacillariophyceae) mats using a novel ${ }^{32} \mathrm{Si}$ autoradiography method. J Phycol 35:995-1004

Strickland JD, Parsons TR (1972) A practical handbook of seawater analysis. Bull Fish Res Board Can 167:310

Taguchi S, Hirata JA, Laws EA (1987) Silicate deficiency and lipids synthesis of marine diatoms. J Phycol 23:260-267

Volcani BE (1981) Cell wall formation in diatoms: morphogenesis and biochemistry. In: Simpson TL, Volcani BE (eds) Silicon and siliceous structures in biological systems. Springer-Verlag, New York, p 157-200

Vrieling EG, Gieskes WWC, Beelen TPM (1999) Silicon deposition in diatoms: control by the $\mathrm{pH}$ inside the silicon deposition vesicle. J Phycol 35:548-559 